\title{
0xidative Stress Manifestation for Community-Acqiured Pneumonia in Children Living in Endemic Area of Iodine Deficiency
}

\author{
Halyna Pavlyshyn ${ }^{2},[\mathrm{MD}],[\mathrm{PhD}]$ \\ Volha Kibar ${ }^{2},[\mathrm{MD}],[\mathrm{PhD}]$ \\ Viktoriia Slyva *, [MD],[PhD]
}

1, I. Ya. Horbachevsky Ternopil State Medical University, Head of the Department of Pediatrics No:2, Ternopil, Ukraine

*Corresponding Author: Viktoriia Slyva
Department of Pediatrics No:2
Ternopil State Medical University named by
I.Horbachevsky
8/112, Zluky Ave., Ternopil, Ukraine
DOI: https://doi.org/10.32552/2018.ActaMedica.306
e-mail: vsliva@hotmail.com

*Corresponding Author: Viktoriia Slyva

Department of Pediatrics No:2

Ternopil State Medical University named by

orbachevsky

DOI: https://doi.org/10.32552/2018.ActaMedica.306

\section{ree) ABSTRACT Cen}

Objective: We aimed to evaluate the state of oxidative stress, level of molecular damage in relationship with the subcellular distribution of iodine in patients with community-acquired pneumonia from the iodine deficiency region.

Materials and Methods: Our study involved 70 children, 4-14 years old, with CAP (moderate severity in 35 children (Group 1); severe - in 35 (Group 2)) and 35 healthy children of the control group (Group 3). The state of organificated/inorganic, antioxidant defense system, stress-dependent systems, apoptosis and the level of molecular damage were assessed in serum samples.

Results: Lower concentration of organificated iodine ( $12 \%$ and $59 \%$, respectively) and high concentration of inorganic iodine ( $21 \%$ and $48 \%$, respectively) were found in Groups 1 and 2. Patients of Group 2 had an inverse relationship between the levels of iodine distribution for the organic and inorganic iodine $(r=-0.645, \mathrm{p}<0.05)$. In patients of Group 1, this relationship tends to decrease. The oxidative stress indicators correlated with disease severity. ROS generation indices in patients of Group 1 is 28.1 (24.2; 32.1) RFU/mg; ( < 0.05); Group 2 - 40.2 (34.2; 42.5) RFU/mg ( $<$ < 0.05); Caspase-3 is 25.77 (21.45-32.16) pmol/mg Group 1 and 39.42 (32.41-44.21) pmol/mg Group 2, (respectively, $\mathrm{p}<0.05$ ). We found that children with a severe pneumonia have a prooxidant activation, manifested by a significant increase of oxidation-modified proteins [2.21 (1.88-2.53) nmol/mg)] and DNA fragmentation [13.42 (10.3-15.46) $\%],(\mathrm{p}<0.05)$. The extent of DNA damage correlates with the extent of apoptosis. Conclusions: Increase in the concentration of inorganic iodine with a simultaneous decrease in the level of organic iodine in the blood, which leads to a more severe course of pneumonia. Fluctuations in the indices of oxidative stress, the level of molecular damage and the intensity of apoptosis in children with pneumonia correlate with the severity of the disease.

Key words: Community-acquired pneumonia, oxidative stress, cytotoxicity, apoptosis, iodine deficiency.

\section{INTRODUCTION}

Community-acquired pneumonia (CAP) in children is one of the most common infectious diseases [1]. Despite significant successes in studying the pathogenesis, diagnosis and treatment of CAP, some aspects of its development, as well as the severity of the course and progression, remain controversial. This leads to search for new markers of the severity of pneumonia, the detection of comorbid conditions, and the study of their effect on the child's body. So, iodine deficiency is a huge impact on the body, in particular on immunological reactivity, especially in populations living in areas of endemic iodine deficiency [2].

lodine and iron deficiency are one of the most common and significant consequences of micronutrient deficiency in the world. The issue of the effect of iron deficiency anemia and latent iron deficiency on immune status of children has been studied sufficiently well. However, iodine deficiency in this aspect is given undeservedly little attention. In children against a background of chronic iodine deficiency, there is an increase in the incidence of tonsillitis, sinusitis, pneumonia, urinary tract infection, which is caused by the inhibition of humoral and 
cellular factors of nonspecific protection. In this case, the infectious process is distinguished by the severity of the flow, the tendency to relapse, the slowing down of the immune response to bacteria and viruses. Violation of humoral, especially local, immunity with iodine deficiency leads to increased adhesion of microbes and viruses to the surface of the mucous membrane, which in the future can lead to its deep structural disorders [3]. Under these conditions, the barrier functions of the mucous membrane decrease, which can cause the generalization of the infectious process [4].

Inadequate intake of iodine in the child's body leads to underproduction of thyroid hormones and the development of hypothyroxinemia. Thyroid hormones play the role of universal regulators of various functions of almost all organs and systems of the body. The immune system is not an exception. A number of experimental studies have shown that, when an adequate level of thyroxine is provided, the adhesion of microorganisms to the cell wall is significantly reduced in the body [5, 6]. Experimental data confirm the indirect involvement of thyroid hormones in the differentiation and regulation of the lifespan of certain immune competent cells, in particular B-lymphocytes responsible for the production of antibodies [7]. In the absence of thyroid hormones, the maturation of lymphocytes is inhibited, their life span decreases, and there is a deficit of immunoglobulins of protective classes. In addition, thyroid hormones stimulate the activity of socalled natural killer cells (NK cells), which take part not only in anticancer, but also in the anti-infective defense of the body [8]. The effect of thyroxin on T-lymphocytes has not been sufficiently studied, but it is known that this hormone has a significant regulating effect on the production of lymphocytes in the thymus (thymus), promoting an increase in cellular immunity [9]. The initial hypothyroxinemia leads to a deficiency of immune defense when generalization of the infectious process in conditions of iodine deficiency. The resulting viremia or bacteremia, in turn, negatively affects the functioning of many organs and systems, including the thyroid gland, leading to a worsening deficit of thyroid hormones [10].

Phagocytes produce active forms of oxygen a significant growth of which is restrained by the antioxidant system of the body during pneumonia process. Damage to proteins, lipids and nucleic acids of the body's own tissues begins with the activation of free radical peroxidation [11]. A significant role in the development of changes in various organs is associated with the formation of products of oxidative modification of proteins or protein peroxidation. It is a nonspecific pathogenetic chain of formation of many pathological conditions in the body. It is reported that oxidative modification of proteins act as markers of endogenous intoxication [12]. In the future, protein peroxidation products stimulate lipid peroxidation, oxidative damage to DNA, disruption of enzymatic processes in the body, the functioning of ion channels and cell receptors, in addition, they themselves have pronounced cytotoxic effects [13]. Thus, pathogenetic processes in pneumonia and the development of its complications, accompanied by oxidative stress, can be considered as indices of pro and antioxidant system activity, directly determining levels of free radical products, elements of the antioxidant system, and markers of DNA damage. Recurrent respiratory infections, reduction of body defenses are often associated with the damaging effects of genotoxicants (dangerous toxic substances, air pollution, natural iodine deficiency, etc.), which consists in damage to the structure of DNA and the induction of various mutations leading to severe course, development of complications and recurrence of the disease [14-17]. In the available literature a little information is given on the genotoxic effect of oxidative stress in CAP under iodine deficiency, which seems appropriate to consider its mechanisms in more detail.

\section{MATERIALS and METHODS}

All patients were divided into three groups. The Group 1 consisted of 35 CAP patients with moderate pneumonia. The Group 2 consisted of 35 CAP patients with severe course of pneumonia with respiratory insufficiency of II - III degree. The age range of participants was 4 and 14 years old. The Group 3 (control group) consisted of 35 healthy volunteers of similar age, who were without signs of any inflammation. Verification of the diagnosis was carried out and based on standard criteria (a laboratory-clinical and instrumental examination). The severity of the condition assessed according to the existing protocols and the Pneumonia Severity Index [18]. All children permanently lived in the region of mild to moderate severity of iodine deficiency and did not have typical complaints of thyroid dysfunction.

All experimental studies were conducted in accordance with the approval of the First National Congress on Bio (Kyiv, 2000) and the approval of the Bioethics Commission of I. Ya. Horbachevsky Ternopil State Medical University (approval № 24 from 27.08.2016). Blood samples were collected in EDTA and plain vacutainer from the control as well as from patients either admitted in the ward or 
visiting pediatric OPD. All estimations were done on serum samples.

Subcellular distribution of iodine in the blood was determined by method $\nabla$ utility model patent № 45332 (UA), MPK G09B 23/28 (2009.01) [19]. Principle of this method is based on the ability of chloroform to extract molecular iodine from an aqueous solution to form a pink product. The intensity of the color of the complex is directly proportional to the amount of iodine in the sample. To determine the total iodine content, blood serum was subjected to alkaline ashing. $0.5 \mathrm{~g} \mathrm{NaOH}$ was melted in a crucible and cooled down. $0.5 \mathrm{ml}$ of blood was placed in cooled $\mathrm{NaOH}$ and heated at $700-800{ }^{\circ} \mathrm{C}$ for 5-7 minutes until homogeneous melt was obtained. 5 $\mathrm{ml}$ of water was added after cooling to the melt and the resulting solution was neutralized with concentrated $\mathrm{H} 2 \mathrm{SO} 4$ to $\mathrm{pH}$ 5-6. Then the reaction mixture was treated with $1.0 \mathrm{ml}$ of $0.50 \mathrm{M}$ sodium nitrite to determine iodine. The iodine was extracted with 4 $\mathrm{mL}$ of $\mathrm{CHCl} 3$ and recorded optical absorption of the sample at a wavelength of $510 \mathrm{~nm}$ [20] iodine content in the sample was determined from the calibration curve constructed on potassium iodide and expressed in $\mu \mathrm{g} / \mathrm{l}$.

To determine inorganic (non-protein) iodine in the blood, $25 \%$ homogenate was made in 10\% trichloroacetic acid solution with the addition of phenylmethylsulfonyl fluoride (0.1 mM, "Sigma") protease inhibitor. The homogenate was centrifuged for 15 minutes at $10,000 \mathrm{rpm}$. The resulting supernatant was incubated with $1.0 \mathrm{ml}$ of $5.0 \mathrm{M} \mathrm{H} 2 \mathrm{SO} 4$ and 1.0 $\mathrm{ml}$ of $0.50 \mathrm{M}$ sodium nitrite. lodine was extracted with $4 \mathrm{~mL}$ of $\mathrm{CHCl} 3$ and recorded optical absorption of the sample at a wavelength of $510 \mathrm{~nm}$. The iodine content in the sample was determined from the calibration curve constructed on $\mathrm{KJ}$ and expressed in $\mu \mathrm{g} / \mathrm{L}$. The number of organic (protein bound) iodine was calculated based on the difference in the content of total and inorganic iodine.

Superoxide dismutase (SOD) activity was measured by the method of Beauchamp and Fridovich [21] based on the aerobic reduction of NBT at $535 \mathrm{~nm}$ by superoxide radicals and expressed as units.mg-1 soluble protein; 1 unit of SOD activity is defined as the amount of protein causing $50 \%$ inhibition of the rate of NBT reduction. Catalase activity was measured by spectrophotometric method [22].

Enzymatic and chromatographic methods were used for the determination of glutathione (GSHt) and oxidized glutathione (GSSG) in the blood. GSH concentration was quantified by the glutathione reductase recycling assay. To estimate the GSSG lev$\mathrm{el}$, the protein free sample was treated with 2-vinylpyridine for $60 \mathrm{~min}$ prior to assay at $2 \%$ final concentration [23]. The redox-index of glutathione (RI GSH) was calculated as the ratio of concentrations [GSHr]/[GSH].

Evaluation of oxyradical production was determined using the non-fluorescent derivative, dihydrorhodamine, which is converted to the fluorescent dye, rhodamine-123, while reacting with reactive oxygen species (ROS). The fluorescence signal was detected by using af-max fluorescence plate-reader [excitation $=485 \mathrm{~nm}$, emission $=538$ $\mathrm{nm}$ ] immediately, and in $20 \mathrm{~min}$.

DNA fragmentation was evaluated by the determination of the levels of protein-free DNA strand breaks in the serum blood by the alkaline DNA precipitation assay [24-25]. Intensity of apoptosis was determined from the activity of caspase-3 [25].

All measurements were carried out using samples from 105 patients. The results were defined as means \pm standard deviation (SD). Since data were not normally distributed (Lilliefors' test), non-parametric tests (Kruskall-Wallis ANOVA and MannWhitney U-test) were performed (significant at $p$ $<0.05$ ). For detection of correlation, the Pearson's correlation test was also performed at a 0.05 level of significance. All statistical calculations were performed by means of Statistica v 10.0.

\section{RESULTS}

Organificated and inorganic iodine was assessed depending on the severity of the clinical course of pneumonia. The results of the studies showed that the content of organic iodine in the blood of children with pneumonia is less, and the concentration of inorganic iodine is higher (especially in severe pneumonia) in comparison with the control group (Table 1).

The most important finding was lower level of organificated iodine (by 11 and $59 \%$, respectively) and higher level (by 27 and $94 \%$, respectively) of inorganic iodine in the Group 1 and Group 2.

Interpretation of the obtained indices by linear regression analysis allows us to conclude that there is a feedback between the levels of intracellular iodine distribution for organic and inorganic iodine $(r$ $=-0.645, p<0.05$ ), which tends to decrease depending on the severity of pneumonia. In patients with moderate severity of pneumonia, this relationship tends to decrease.

Oxidative stress resulting from an imbalance between the formation and neutralization of active forms of oxygen is considered a nonspecific sign of the effect of adverse factors of different origin on the human body. The study of the oxidative status of children with CAP showed that the production of 
ROS in children with moderate and severe course of CAP exceeds in 1.3 and 2 times when compared to the control group $(p \otimes 0.05)$.

Table 1. Subcellular distribution of iodine in children's blood, Median (min-max)

\begin{tabular}{|c|c|c|c|c|}
\hline \multicolumn{2}{|l|}{ Parameter } & $\begin{array}{l}\text { Moderate CAP } \\
\text { (Group 1), } \\
n=35\end{array}$ & $\begin{array}{c}\text { Severe CAP } \\
\text { (Group 2), } \\
n=35\end{array}$ & $\begin{array}{c}\text { Control group } \\
\text { (Group 3), } \\
n=35\end{array}$ \\
\hline \multirow[t]{2}{*}{$\begin{array}{l}\text { iodine distribution in } \\
\text { the blood }\end{array}$} & $\begin{array}{l}\text { organificated iodine, } \\
\mu \mathrm{g} / \mathrm{g}\end{array}$ & $122.1(119.3 ; 127.3)^{1} \nabla^{3}$ & $86.1(79.3 ; 93.9)^{2}$ & $136.75(132.45 ; 144.75)$ \\
\hline & inorganic iodine, & $9.8(8.2 ; 11.2)^{1} \nabla^{3}$ & $14.9(13.8 ; 15.7)^{2}$ & $7.7(7.55 ; 8)$ \\
\hline
\end{tabular}

Table 2. State of stress-responsive systems and genotoxicity in observed children, Median (min-max

\begin{tabular}{|c|c|c|c|}
\hline Parameter & $\begin{array}{c}\text { Moderate CAP } \\
\text { (Group 1) } \\
n=35\end{array}$ & $\begin{array}{c}\text { Severe CAP } \\
\text { (Group 2), } \\
n=35\end{array}$ & $\begin{array}{l}\text { Control group } \\
\text { (Group 3), } \\
n=35\end{array}$ \\
\hline Mn-SOD activity, IU.mg & $3.91(2.7 ; 4.69)^{1}$ & $2.04(1.61 ; 3.51)^{2}$ & $2.82(2.62 ; 2.87)$ \\
\hline Catalase activity, $\mathrm{mmol} \cdot \mathrm{min} \cdot \mathrm{mg}$ & $345.69(307.16 ; 381.11)$ & $\begin{array}{c}472.91(444.13 ; 531.84) \\
2\end{array}$ & $326.82(317.11 ; 340.41)$ \\
\hline Oxyradicals content, & $28.1(24.2 ; 32.1)^{1}$ & $40.2(34.2 ; 42.5)^{2}$ & $22.15(20.15 ; 24.1)$ \\
\hline Reduced glutathione (GSH), $\mu \mathrm{mol} / \mathrm{L}$ & $1.85(1.72-1.99)$ & $1.68(1.64-1.76)^{2}$ & $1.915(1.79-1.96)$ \\
\hline Oxidized glutathione (GSSH), $\mu \mathrm{mol} / \mathrm{L}$ & $0.18(0.17-0.19)$ & $0.24(0.22-0.27)^{2}$ & $0.145(0.135-0.158)$ \\
\hline Redox-index of glutathione, IU & $0.907(0.883-0.917)^{1}$ & $0.817(0.805-0.829)^{2}$ & $0.936(0.921-0.947)$ \\
\hline Caspase-3, pmol / mg & $25.77(21.45-32.16)^{1}$ & $39.42(32.41-44.21)^{2}$ & $16.8(14.37-18.86)$ \\
\hline Content of fragmented DNA in total DNA, \% & $7.9(7.3-9.8)$ & $13.42(10.3-15.46)^{2}$ & $7.1(6.3-7.45)$ \\
\hline $\begin{array}{l}\text { Formation oxidative modification of pro- } \\
\text { teins, } \mathrm{nmol} / \mathrm{mg}\end{array}$ & $1.27(1.16-1.49)$ & $2.21(1.88-2.53)^{2}$ & $1.11(1.11-1.32)$ \\
\hline \multicolumn{4}{|c|}{ Note: ${ }^{1}$ Group 1 versus Group 3 ( $\left.p<0.05\right),{ }^{2}$ Group 2 versus Group 3 ( $\left.p \bowtie 0.05\right)$. } \\
\hline
\end{tabular}

The results of an evaluation of antioxidant defense system state (Table 2) show that SOD activity in the severe course of CAP is lower (by $28 \%$ ) than in controls. The catalase activity higher (by $45 \%$ ) and reduced GSH level (by $12 \%)$ are lower in severe pneumonia. At the same time, the intensity of the ROS formation (by $82 \%$ ) and the lowest concentration of oxidized glutathione (by $66 \%$ ) are higher in patients with severe CAP compared to the control samples. Moreover, the redox index of glutathione is equal to 0.936 in control and 0.817 in severe CAP and 0.907 in patients with moderate pneumonia. Thus, progressive disorders from glutathione metabolism and subsequent changes in thiol-disulphide balance were detected in patients with severe CAP.

When studying the same indicators in patients with moderate CAP we found the coherent activation of superoxide dismutase (by $40 \%$ ), which indicates the compensatory power of the antioxidative systems. Catalase activity was a trend of increasing in all CAP patients, when compared to the control group which facilitates the activation of Lipid peroxidation processes and the compensatory response of these enzymes. A relation between activation of catalase and ROS formation level in CAP patients was proved. In studying correlations in CAP patients, a reverse link between production of ROS and activation of catalase was revealed $(r=0.600, p<0.05)$. This correlation was depending on the severity of pathological process at pneumonia. In particular, at moderate pneumonia the level of these indexes diminishes.

While determining the level of oxidative modified proteins a statistically significant increase in severe course of CAP patients, in comparison to control group values, was found $(p<0.05)$. However, the oxidative modification of proteins concentration did not differ in moderate pneumonia from control values and are not statistically significant ( $p \otimes 0.05)$. 
We have established the effect of the severity of the inflammatory process in pneumonia on the indicators of geno- and cytotoxicity. The signs of cytotoxicity are determined in both groups with CAP: an increased (compared to control) level of DNA fragmentation (by $11.3 \%$ Q in moderate pneumonia and up to $89 \%$ in severe CAP) and activation of caspase-3 activity (up to $53.4 \%$ and 135 $\%$ in moderate and severe CAP respectively).

The correlation between the content of catalase and level of DNA strand breaks $(r=0.54, p<0.01)$ and between the activity of SOD and the intensity of formation of ROS $(r=0.56, p<0.01)$ were established.

\section{DISCUSSION}

It is generally known that iodine deficiency develop in pathologically affected immune system. We suspected that hyperplastic thyroid epithelium under iodine deficiency sacrificed its ability for iodine organification and therefore increased of level of inorganic iodine [26].

According to scientific literature one of the markers of oxidative stress is the processes of oxidative modification of proteins of blood serum [10, 27]. We found a reduced ability of the body to organificate iodine and increase in oxyradical and oxidative modification of proteins and increased DNA fragmentation in patients with severe CAP. This leads to activation of antioxidant protection. Activation of the catalase $(r=0.49, p<0.01)$ and an increase in the level of DNA damage $(r=0.86, p<0.01)$ is noted against a background of increased concentration of inorganic iodine in the blood.

Finally, in studying correlations this pattern designated with higher inorganic iodine level $(r=0.69, p<0.01)$, manifestation of oxidative damage (increased of catalase and GST activity ( $r=0.49$ and $r=0.64$ correspondingly, $p<$ 0.01 and caspase- 3 activity $(r=0.97, p<0.01)$ ) and cytotoxicity (increased DNA fragmentation, $r=0.86, p<0.01$ ) in patients with severe pneumonia. The nature of these changes in the group of children with moderate pneumonia is less and statistically insignificant ( $p \otimes 0.05$ ).

We have established an increase in the level of damage to DNA, ROS formation and apoptosis (with the activity of caspase-3) with severe course of CAP, which in turn leads to activation of antioxidant protection.

In this way, children lived in regions where iodine deficiency is endemic have latent iodine deficiency in the body, which is exacerbated by the severity of the inflammatory process. When the compensatory possibilities of hypertrophied thyrocytes are depleted (during iodine deficiency) the iodide is dissolved in the human body, which leads to its excess and formation of toxic intermediate iodide formations in the body $[6,8]$. Therefore, it can be assumed that under deprivation of iodine organification surplus of it has been created in human thyroid gland and determined further formation of iodine toxic intermediates in hyperplastic thyrocytes after its oxidation by thyroperoxidase [28]. In turn, this leads to the activation of antioxidant protection.

Long-term residence in iodine deficient regions contribute to a gradual reduction iodine content in the human body. These changes lead to gradual hyperplasia of the epithelium of thyroid cells. Which lose the ability to organize all iodine in the gland and bring to excessive accumulation of inorganic iodine in organs and tissues, blood serum, hair, urine [26]. As a result, there is a shortage of "building material" for thyroid hormones and the development of hypothyroxinemia. There is a battle in the regulation of the immune system with increased adhesion of microorganisms to the cell wall and a marked decrease in the anti-infection protection of the child's body. A more severe course of CAP is observed in children with identified iodine deficiency and the incidence of development of complications increases significantly (p冈0.05) $[4,5]$.

\section{CONCLUSIONS}

To summarize, the most significant changes of the organification of iodine with increases the content of inorganic iodine were found in patients with severe course of pneumonia.

The severe course of pneumonia in children is characterized by high level of inorganic iodine. This leads to the activation of the antioxidant defense system with a high formation of ROS and excessive generation of oxidative modification of serum proteins. This confirms the intensity of oxidative stress with increasing cytotoxicity (increased level of DNA fragmentation) and destabilization of cell membranes, inactivation of enzyme systems, which may serve as an additional diagnostic criterion for the severity of community-acquired pneumonia in children.

Components of the glutathione system and oxidative modification of proteins affect the activation of apoptosis, by increasing the activity of caspase- 3 in conditions of redox status change in the body of children with community-acquired pneumonia.

\section{CONFLICT OF INTEREST STATEMENT}

The authors report no conflict of interest. 
[1] Revised WHO Classification and Treatment of Pneumonia in Children at Health Facilities. Evidence Summaries. Geneva: World Health Organization. 2014. http://apps.who.int/iris/bitstream/10665/137319/1/9789241507813_eng.pdf. Accessed January 23, 2018.

[2] Zimmermann MB, Andersson M. Update on iodine status worldwide. Curr Opin Endocrinol Diabetes Obes. 2012; 19: 382-387.

[3] Zhu XH., Chen Q, Ke J.W, et al. Clinical analysis of immune function changes in children with bronchial pneumonia. Zhongguo Dang Dai Er Ke Za Zhi. 2013; 15(3): 175-178.

[4] Steel HC, Cockeran R, Anderson R, et al. Overview of Community-Acquired Pneumonia and the Role of Inflammatory Mechanisms in the Immunopathogenesis of Severe Pneumococcal Disease. Mediators of Inflammation. 2013; 2013:490346. doi:10.1155/2013/490346.

[5] De Vito P, Incerpi S, Pedersen JZ, et al. Thyroid hormones as modulators of immune activities at the cellular level. Thyroid. 2011; 21(8): 879-90.

[6] Alamino VA, Montesinos MM, Rabinovich GA, et al. The thyroid hormone triiodothyronine reinvigorates dendritic cells and potentiates anti-tumor immunity. Oncoimmunology. 2016; 5(1): 23-29.

[7] Olivo-Vidal ZE, Rodriguez RC, Arroyo-Helguera O. lodine affects differentiation and migration process in trophoblastic cells. Biol Trace Elem Res. 2016; 169(2): 180-188.

[8] Ma ZF, Skeaff SA. Thyroglobulin as a biomarker of iodine deficiency: a review. Thyroid. 2014; 24(8): 1195-209.

[9] Szybinski Zbigniew. Role of lodine in Metabolism. Recent Patents on Endocrine, Metabolic \& Immune Drug Discovery. 2016; 10(2): $123-126$.

[10] Zhiyou C, Liang-Jun Y. Protein oxidative modifications: beneficial roles in disease and health. J Biochem Pharmacol Res. 2013; 1: 15-26.

[11] Hassoun EA, Ray S. The induction of oxidative stress and cellular death by the drinking water disinfection by-products, dichloroacetate and trichloroacetate in J774.A1 cells. Comp. Biochem. Physiol. 2003; 135(2): 119-128.

[12] Bordon J, Aliberti S, Fernandez-Botran R, et al. Understanding the roles of cytokines and neutrophil activity and neutrophil apoptosis in the protective versus deleterious inflammatory response in pneumonia. Int. J. Infect. Dis. 2013; 17(2): 76-83.

[13] Rai P, Parrishc M, Tay IJ, et al. Streptococcus pneumoniae secretes hydrogen peroxide leading to DNA damage and apoptosis in lung cells. Proc Natl Acad Sci U S A. 2015; 112: $3421 \otimes 3430$.

[14] Wu $M$, Huang $H$, Zhang $W$, et al. Host DNA repair proteins in response to Pseudomonas aeruginosa in lung epithelial cells and in mice. Infect Immun. 2011; 1(79): 75-87.
[15] Chumduri C, Gurumurthy RK, Zadora PK, et al. Chlamydia infection promotes host DNA damage and proliferation but impairs the DNA damage response. Cell Host Microbe. 2013; 6(13):746-758.

[16] Mittal M, Siddiqui M.R, Tran K, et al. Reactive oxygen species in inflammation and tissue injury. Antioxid. Redox. Signal. 2014; 20(7): 1126-1167.

[17] Bordon J. Understanding the roles of cytokines and neutrophil activity and neutrophil apoptosis in the protective versus deleterious inflammatory response in pneumonia. Int. J. Infect. Dis. 2013; 17(2): 34-41.

[18] Harris M, Clark J, Coote N, et al. British Thoracic Society guidelines for the management of community acquired pneumonia in children: update 2011. Thorax. 2011;66:1-23.

[19] Shidlovs'kij VO, Stoljar OB, Osadchuk DV. Method for determining the concentration of iodine in a biosubstrate. UA patent 45332. 2009 Nov 10. [Ukranian].

[20] Saar VG, Koroleva EM, Nikitina TG. Photomentric determination of iodine in biological samples of complicated compositions. Pharm. Chem. J. 2000; 34(8): 448-450.

[21] Beauchamp C, Fridovich I. Superoxide dismutase: improved assay and an assay applicable to acrylamidegels. Anal Biochem. 1971; 44: 276-287.

[22] Aebi H. Catalase in Bergmeyer Hans Ulrich. Methods of Enzymatic Analysis. London: Academic Press; 1974:671-684.

[23] Anderson ME. Determination of glutathione and glutathione disulfide in biological samples. Meth Enzymol. 1985; 113: 548-555.

[24] Olive PL. DNA precipitation assay: a rapid and simple method for detecting DNA damage in mammalian cells. Environ. Molec. Mutagen. 1988; 11(4): 487-495.

[25] Bonomini M, Dottori S, Amoroso A, et al. Increased platelet phosphatidylserine exposure and caspase activation in chronic uremia J. Thromb. Haemost. 2004; 2(8): 1-8.

[26] Falfushynska $H$, Gnatyshyna L, Shulgai A, et al. Oxidative stress in human thyroid gland under iodine deficiency nodular goiter: from harmlessness to hazard depending on copper and iodine subcellular distribution. International Journal of Medicine and Medical Research. 2015; 1(1): 5-11.

[27] Zhiyou C, Liang-Jun Y. Protein oxidative modifications:beneficial roles in disease and health. J Biochem Pharmacol Res. 2013; 1: 15-26.

[28] Vitale M, Di Matola T, D'Ascoli F, et al. lodide excess induces apoptosis in thyroid cells through a p53-independent mechanism involving oxidative stress. Endocrinology. 2000; 141: 598-605. 